\title{
A narrativa como ferramenta na educação médica
}

\author{
The narrative as a tool in medical education \\ La narrativa como una herramienta en la educación médica
}

Eloisa Grossman," Maria Helena C. A. Cardoso

\begin{abstract}
Resumo
O objetivo do artigo é discutir o papel da narrativa como uma ferramenta na educação médica. As autoras argumentam que o método utilizado pelos médicos para cuidar de seus pacientes tem raízes muito antigas. Os caçadores foram os primeiros a recorrer à narrativa para difundir o conhecimento adquirido a partir da interpretação de pistas e vestígios deixados pelos animais. Desenvolveram, assim, um modelo de conhecimento indireto, indiciário e conjetural, que garantia a sobrevivência. Esse método é, também, o fundamento da semiologia e da difusão do saber médico. Em seguida, discorrem sobre as diferentes modalidades narrativas empregadas na prática e no ensino da medicina e elencam suas principais características. A classificação proposta inclui: casos construídos com propósito educativo (método PBL), narrativas de pacientes sobre suas doenças, narrativas apresentadas em materiais informativos (cartilhas, folhetos, cartazes, websites e blogs), anamneses sistematizadas em prontuários e relatos de caso apresentados em sessões clínicas e em revistas científicas. Concluem afirmando que médicos escutam e escrevem, fazem leituras de sinais e de métodos complementares em seu cotidiano de trabalho. Habitam o universo da palavra oral, da palavra escrita e das imagens. A legitimação da importância da competência narrativa na formação dos estudantes de medicina parece ser um caminho profícuo para aproximá-los do mundo dos pacientes e ajudá-los a entender o que a doença representa para cada indivíduo em particular.
\end{abstract}

Descritores: Medicina narrativa; Educação médica.

\begin{abstract}
This article discusses the role played by narratives as a tool on medical education. The authors suggest that the method used by physicians to take care of their patients has very ancient origin. The hunters were the first to tell a story to transmit the knowledge learned from the interpretation of clues and traces left by animals. They developed a model of knowledge indirect, presumptive and conjectural, whichensures their survival. This method is also a fundamental structure of medical semiology and of the transmission of medical knowledge.Subsequently the authors propose a classification of medical narratives used on practice and medical teaching based on their main features. It includes: problem based learning case studies, patient's illness narratives, narratives on informative texts (booklets, brochures, posters, websites and blogs), anamnesis ordered on patient's charts, clinical case presentations and publication in scientific journals. The conclusion emphasizes that doctors hear and write stories, read signals and complementary tests in their day working. Live in the universe of oral and written words, and pictures. The legitimacy of the relevance of the narrative competence in the training of medical students seems to be a useful pathway to bring them to the world of the patient and to help them understand what the disease represents for each person in particular.
\end{abstract}

Keywords: Narrative medicine; Education, Medical. 


\section{Resumen}

El objetivo del artículo es el de discutir el papel de la narrativa como una herramienta en la educación médica. Los autores sostienen que el método utilizado por los médicos para el cuidado de sus pacientes tiene raíces muy antiguas. Los cazadores fueron los primeros en recurrir a la narrativa para difundir el conocimiento adquirido a partir de la interpretación de huellas y rastros dejados por los animales. Así, desarrollaron un modelo de conocimiento indirecto, indiciario y conjetural, que garantizaba la sobrevivencia. Ese método es, también, el fundamento de la semiología y de la difusión del saber médico. Posteriormente, reflexionan sobre las diferentes modalidades narrativas empleadas en la práctica y en la enseñanza de medicina, enumerando sus principales características. La clasificación propuesta incluye: casos construidos con fines educativos (método PBL), narrativas de pacientes sobre sus enfermedades, narrativas presentadas en materiales informativos (cartillas, folletos, carteles, sitios webs y blogs), anamnesis sistematizadas en prontuarios y relatos de caso presentados en sesiones clínicas y en revistas científicas. Concluyen afirmando que los médicos escuchan y escriben, hacen lecturas de signos y de métodos complementarios en su trabajo diario. Habitan el universo de la palabra oral, de la palabra escrita y de las imágenes. La legitimación de la importancia de la competencia narrativa en la formación de los estudiantes de medicina parece ser un camino fructífero para aproximarlos al mundo de los pacientes y ayudarlos a entender lo que la enfermedad representa para cada individuo en particular

Palabras clave: Medicina narrativa; Educación médica.

\section{Introdução}

Para sobreviver, durante milhares de anos os homens precisaram ser caçadores. Para alcançar suas presas, aprenderam a identificar, reconhecer e classificar as suas pegadas na neve, no barro ou na areia. Aprenderam também, utilizando os sentidos, a diferenciar sons, a discernir texturas, a distinguir sabores e odores. Através da observação cuidadosa e do registro das pistas, aparentemente insignificantes quando interpretadas de forma isolada, mas imprescindíveis à construção do todo, foram capazes de garantir sua sobrevivência e a de seus descendentes. A realidade experimentada indiretamente precisava, para o viver humano em coletividade, ser compartilhada, difundida e, por isso, como sugere Ginzburg, os caçadores foram os primeiros a contar uma história, ordenando uma série de acontecimentos no tempo e no espaço. Sem o saber, nesse processo, elaboraram um modelo de conhecimento indireto, indiciário e conjetural, empregado até hoje na medicina.

Se a medicina ocidental, em sua origem, centrou-se numa visão do homem como um ser dotado de corpo e espírito, hoje os avanços tecnológicos parecem ter minimizado a importância da anamnese e do exame físico na semiologia médica. Para cuidar de uma pessoa enferma há que se recuperar a ênfase nas pistas infinitesimais inscritas nas experiências individuais de adoecimento. Nesse sentido, atentar para o que os pacientes e seus corpos doentes nos narram nos aproxima do modelo desenvolvido pelos nossos ancestrais caçadores. Assim, coletar pistas, ordená-las e classificá-las constitui a base do exercício diagnóstico e terapêutico.

Ouvir e contar histórias, reconhecer sinais e sintomas, enxergar além das aparências, fazer perguntas e entender o significado de tudo o que foi recolhido no encontro com o paciente são ações do cotidiano do médico. Por isso, o estudo das narrativas e o desenvolvimento de sujeitos com essa competência são atividades centrais no ensino médico e, em última instância, na assistência à saúde da população.

Hoje há forte sustentação acadêmica da importância do estudo das narrativas como uma atividade central na prática e no ensino da medicina. ${ }^{2}$ Conceitualmente, medicina e narrativa caminham juntas, visto que múltiplas possibilidades narrativas são geradas pela doença: o adoecimento por ele mesmo, inscrito nos corpos; a descrição autobiográfica dos pacientes; a transformação dos relatos destes pelos médicos e o próprio curso da doença, expondo relações entre linguagem, soma, indivíduo e tempo. ${ }^{3}$

Discutir as diferentes formas narrativas presentes na formação/informação médica parece ser um caminho profícuo para aproximar o aluno do mundo do paciente, e não apenas do mundo da doença. 


\section{As diferentes modalidades}

\section{narrativas em medicina}

Rita Charon alerta que a relação entre médicos, pacientes e seus familiares envolve a necessidade do desenvolvimento da competência narrativa. A narrativa, segundo ela, é central à compreensão e ao manejo das doenças, dado que estas possuem uma evolução temporal característica, complexas misturas de contingência e causalidade, semelhanças e diferenças em relação a outras enfermidades, uma herança sociocultural discursiva que as situa e um conjunto de metáforas que as explicam. ${ }^{4}$ Considerando-se tais elementos, o presente texto foi elaborado para auxiliar na caracterização das diferentes formas de narrativa utilizadas na prática e no ensino médicos.

\section{Casos construídos com propósito educativo}

O método Problem Based Learning (PBL) Aprendizado Baseado em Problemas - é uma estratégia didática centrada no aluno. Foi desenvolvido objetivando substituir aulas expositivas descontextualizadas em relação ao mundo real. Aplicado em escolas médicas nos últimos 30 anos, é considerado um método bastante eficaz. ${ }^{5}$

O problema é a pedra de toque e, enquanto tal, deve ser formulado de modo simples, objetivo, motivador e propor situações sobre as quais o aluno possua algum conhecimento ou vivência prévia. Centrando-se na articulação entre teoria e prática, direciona-se à formação de profissionais autônomos, capazes de procurar e selecionar informações, utilizando-as criticamente na estruturação do raciocínio clínico e da consequente tomada de decisão.

Os casos apresentados são histórias construídas, cujo enredo desenrola-se em torno de uma situação central e de uma sequência de eventos por ela desencadeados. Basicamente devem valorizar o conhecimento advindo da prática, o método hipotético dedutivo, ${ }^{6}$ os julgamentos e condutas médicas.

Nessa modalidade narrativa, o real e o imaginado se mesclam para constituir um caso emblemático, situado em contextos específicos.
O PBL apresenta algumas vantagens quando comparado às aulas expositivas: maior retenção de informação; desenvolvimento de conhecimentos integrados; estímulo à educação continuada; introdução à experiência clínica em diferenciadas etapas curriculares; fortalecimento do vínculo professor-aluno, ampliando a motivação entre eles, por via da troca profícua de experiências. ${ }^{?}$

\section{Narrativas de pacientes sobre suas doenças}

As narrativas de pacientes sobre suas doenças incluem fragmentos de histórias de vida, relatos da doença e de rupturas por ela impostas e, especialmente, os esforços individuais e coletivos despendidos para a adaptação, transformação e, talvez, superação dos entraves ditados pelo sentir-se enfermo.

Kleinman, autor da expressão "ilness narratives", afirma ser esta a forma pela qual os pacientes dão significado aos seus sofrimentos. ${ }^{8}$ Frank defende a ideia de que ao narrar a doença, os fatos transformam-se em experiências. Uma mesma doença que segrega e estigmatiza é convertida num elo de sofrimento compartilhado, aproximando corpos e vulnerabilidades, ou seja, socializando o particular. ${ }^{9}$

Hawkins, centrando-se no que denomina patografias - narrativas escritas por pacientes e posteriormente publicadas -, distingue três tipos de argumentação típicas desse gênero literário: a "didática", baseada numa experiência vivida contada aos outros para ofertar confiança e esperança; a "irritada", dirigida à revolta contra a dor gerada por procedimentos médicos invasivos de diagnose e tratamento e, por último, o tipo de argumentação nomeado por ela como "de positividade da mente", isto é, aquele que louva a integração corpo/mente, realçando sobretudo as funções curativas das maneiras positivas de pensar..$^{10}$

O aumento da prevalência das doenças crônicas e degenerativas, bem como o seu papel de destaque nos perfis de morbimortalidade, modificou o papel do profissional de saúde no cuidado de seus pacientes, visto que a cura é a meta sonhada, mas dificilmente alcançada. As patografias ganharam relevância no estudo de doenças crônicas como 
um recurso para o entendimento do esforço empreendido pelos pacientes para lidar com suas situações de vida cotidiana e, acima de tudo, com os problemas de identidade que a doença edita. ${ }^{11}$ Segundo Morris, pesquisador que elaborou a noção "biocultural" da doença, a narrativa não substitui o laser, mas é fundamental à apreensão dos fatores ambientais que contribuem para o surgimento das enfermidades, auxiliando pessoas que sofrem de doenças incuráveis, sobre as quais a medicação pouco atua. ${ }^{12}$

Para Bury, por sua vez, as narrativas sobre doenças dividem-se em três grupos distintos: narrativas contingentes, morais e centrais. As primeiras expõem mitos e crenças acerca da gênese da doença e seu efeito nas condições de vida. As do segundo grupo descrevem as mudanças mediadas pela relação entre indivíduo, doença e sua identidade social, assim como os caminhos para o (re)estabelecimento do status moral. As últimas falam das conexões entre as experiências leigas individuais e os níveis mais profundos de significação do sofrimento e da doença. ${ }^{13}$

\section{Narrativas apresentadas em materiais informativos}

A partir da interação entre a comunicação e a educação, são produzidos os materiais informativos dirigidos ao público leigo (pacientes, familiares e curiosos). Dentre eles, estão incluídos as cartilhas, os folhetos, os cartazes, os websites e blogs, nos quais o discurso científico aparece diluído e mesclado à linguagem literária. A comunicação se dá através da escrita, porém a imagem alcança papel de destaque. Precisam ser claros e objetivos, para possibilitar uma comunicação autoexplicativa. A narrativa inclui exposições, discussões, explanações, descrições e processos, cada qual com diferentes funções e objetivos. As exposições apresentam um ângulo de uma argumentação, usualmente apresentado com a finalidade de atrair o leitor para um determinado ponto de vista; as discussões exploram os dois lados de um argumento; as explanações explicam algo ao leitor; as descrições expõem detalhadamente alguém ou alguma coisa e os processos proporcionam instruções sobre como realizar algo. ${ }^{14}$
A internet vem assumindo papel de destaque como fonte de informação em saúde. ${ }^{15} \mathrm{O}$ diálogo entre pacientes e profissionais de saúde, assim como a troca de experiências entre pacientes com problemas semelhantes, é apontado como uma poderosa estratégia para auxiliar no manejo de diversas condições clínicas, oferecendo melhoria na qualidade de vida, promovendo maior autonomia, proatividade e autoconfiança. ${ }^{16}$

\section{Anamneses sistematizadas em}

\section{prontuários}

O padrão da história clínica, com variações mínimas, inclui informações de identificação, queixa principal, história da doença atual (HDA), história patológica pregressa, revisão dos sistemas, história familiar e história social. Na HDA, os profissionais organizam as queixas do paciente em uma série de pistas diagnósticas, fundamentais para o raciocínio clínico e para o levantamento de hipóteses diagnósticas.

Entretanto, a narrativa construída pelo profissional, à primeira escuta, não ecoa como uma história. A tradução médica da experiência real de adoecimento contada pelo paciente não se assemelha a uma fração da vida de uma pessoa. Habitualmente, tem o formato de um registro burocrático, cujo narrador é um observador neutro e objetivo dos fatos narrados. A aflição que motiva o paciente a procurar o atendimento é formatada em um recontar médico, versão aplanada da história original. Os motivos que o levaram a buscar assistência são preteridos. O medo do paciente, por exemplo, de que seja uma coisa séria, que o afaste do trabalho e dos compromissos assumidos, é desprezado.

A experiência do paciente é codificada em um diagrama, com o objetivo de eliminar aquilo que o médico julga irrelevante e iluminar os conceitos fisiopatológicos.

Cardoso diz ser o prontuário o depositário da primeira narrativa médica; é com base nele que os casos médicos são apresentados. Texto, imagem, números e gráficos se misturam em uma narrativa "econômica", mas inegavelmente individualizada. Além dos eventos relacionados à doença, constam informações sobre inserção social e hábitos alimentares, bem como, de for- 
ma direta ou indireta, são estabelecidas relações causais entre os eventos selecionados. ${ }^{17}$

\section{Relatos de casos em sessões clínicas/casos apresentados em revistas científicas}

Apesar dos avanços no conhecimento biomédico, o relato de casos particulares continua sendo a base para a educação médica e uma importante motivação para a pesquisa clínica. Através deles, ocorre o diálogo entre médicos sobre seus pacientes e suas doenças, métodos diagnósticos, terapêuticas instituídas e resultados alcançados.

Hunter, uma das precursoras no estudo das narrativas como ferramenta conceitual para a medicina, diz que as apresentações de casos seguem rigorosamente convenções previamente estabelecidas. Elas são narrativas cuidadosamente ordenadas, descritivas e pobres em emoção, o que assegura o distanciamento afetivo, considerado adequado para o objetivo a ser alcançado. Ressaltam, ainda, os padrões de evidência, o que, em última instância, possibilitará a identificação do enigma posto pela doença e, consequentemente, o seu manejo. ${ }^{18}$

As apresentações de caso procuram traduzir a experiência de adoecimento do paciente, subjetiva e privada, em uma outra, objetiva e científica, através da interpretação individual do médico. São, sob outro ponto de vista, tentativas de transformar o sofrimento do paciente em uma versão medicamente reconhecível e confiável. ${ }^{18}$

Tradicionalmente, o conhecimento médico, desde Hipócrates até hoje, é desenvolvido e transmitido através de relatos de caso. Podem ser apresentações detalhadas de um único caso ou de poucos casos, e representam uma estratégia importante de apresentação de doenças e suas manifestações, especialmente aquelas mais raras, ao conhecimento médico.

Segundo Donnelly, as apresentações de caso encerram práticas de linguagem inadequadas:

- caracterização do paciente através da descrição estrita de seu transtorno biológico;

- versão da queixa principal do paciente em linguagem biomédica;

- utilização de artifícios retóricos que, de forma repetitiva, elevam a credibilidade do discurso médico e dos resultados de exames laboratoriais e lançam dúvidas sobre a confiabilidade dos testemunhos dos pacientes.

Nestes relatos o paciente "fala", "refere", "declara", "afirma”, "nega”; em contraste, os médicos "registram", "observam", "encontram". Nas informações derivadas de exames complementares são utilizados os verbos "demonstrar" e "revelar", conferindo-lhes o status de uma prova científica, fidedigna e independente de interpretação. Outro subterfúgio bastante utilizado é a voz passiva. Por exemplo, "o baço foi palpado", ao invés de "palpei o baço". Assim, afasta-se a possibilidade de haver uma falha humana, cometida por um indivíduo particular: o médico. ${ }^{19}$

Charon argumenta que, embora o médico tenha pretensões de estar distanciado e ser onisciente em suas narrativas, é inegável o fato de que ele "habita" seu conjunto de motivos, medos, esperanças e que, consequentemente, a narrativa por ele produzida é limitada por seu ângulo de visão. Segundo a autora, as narrativas produzidas, em geral, possuem alguma semelhança e se caracterizam por determinados atributos, tais como:

- A conversão da história do paciente em relatos focados exclusivamente na instalação e curso da disfunção biológica atual. A exclusão das percepções, do significado atribuído, da compreensão do paciente a respeito de sua doença e dos seus efeitos na vida cotidiana aponta para uma postura que desconsidera os medos, as dúvidas e o sofrimento.

- A categorização daquilo que é dito pelo paciente como subjetivo, em contraposição à objetividade dos achados de exame físico e resultados laboratoriais.

- A classificação nosológica dos pensamentos e sentimentos dos pacientes. Um exemplo clássico é traduzir "tristeza" como "depressão".

- A falência em registrar importantes mudanças de perspectiva e decisões do paciente; por exemplo, as opiniões de pacientes portadores de doenças terminais a respeito da permanência em unidades de terapia intensiva e da realização de manobras invasivas. ${ }^{3}$ 


\section{Conclusão}

Narrar é uma manifestação que acompanha o homem desde a sua origem. As narrativas estão estruturadas sobre cinco elementos, quais sejam: os fatos, os personagens, o tempo, o espaço e o narrador. O último se configura como o elemento organizador de todos os outros componentes; o intermediário entre o narrado e o autor, e entre o narrado e o leitor.

Este artigo apresentou com ênfase o narradormédico, herdeiro do narrador-caçador. Em linhas gerais, apresentou o médico, leitor e narrador, decodificador de palavras, de corpos plenos de signos e de imagens. A partir de um conceito bakhtiniano, heteroglossia ou plurilinguismo, os signos não apenas refletem o mundo, mas também o refratam. Através deles é possível construir diversas interpretações (refrações), fruto do caráter diverso e heterogêneo das experiências concretas dos grupos humanos..$^{20}$ No amálgama de histórias, signos, reflexões e refrações são, então, construídas as narrativas em medicina.

Utilizando-nos das ferramentas da crítica literária, distinguem-se variantes do narrador: o que está fora dos fatos narrados, o narradorobservador, geralmente onisciente e um outro, o narrador-personagem, testemunha ou protagonista. Conforme evidenciado na apresentação sobre as diferentes modalidades narrativas, percebe-se que há uma variação nas posições adotadas pelo narrador-médico, bem como, no tipo de linguagem por ele utilizada. Narrativas emocionadas que visam atrair a plateia; narrativas formais em prol de um discurso científico; e narrativas neutras, armaduras protetoras contra o envolvimento emocional são alguns dos exemplos.

As pessoas expressam-se pelo olhar, pelo toque, pela fala, pelo corpo, até pela "não expressão". Aventurar-se neste universo exige dos profissionais de saúde encontrar formas adequadas de olhar, ouvir, sentir e interpretar. Para isso, não poderão lançar mão de "receitas prontas e universais", desvalorizando as singularidades de cada um e as diversidades atreladas a contextos socioculturais plurais.

Dimensões éticas e humanísticas, educação dos sentidos, sujeitos e subjetividades são algumas das tantas maneiras de expressão da pungen- te necessidade de inclusão de tais dimensões no cotidiano do trabalho médico. A distinção entre "doença" e "estar doente" é destacada na língua inglesa, quando se distingue "disease" (doença) de "illness" (estar doente). Se o profissional de saúde não se acercar do mundo do paciente, lidará apenas com uma doença. A ênfase nas narrativas em medicina na formação de estudantes de medicina parece ser um caminho profícuo para aproximá-los do mundo dos pacientes e ajudá-los a entender o que a doença representa para cada indivíduo em particular.

\section{Referências}

1. Ginzburg, C. Mitos, emblemas, sinais: morfologia e história. $2^{\text {a }}$ ed. São Paulo: Companhia das Letras; 2012. 281p.

2. Kottow M. Literary narrative in medical practice. J Med Ethics: Medical Humanities. 2002;28:41-4.

3. Charon R. Literary Concepts for Medical Readers: Frame, Time, Plot, Desire. In: Hawkins AH, McEntyre MC, editors. Teaching literature and medicine. New York: Modern Language Association of America; 2000. p.29-42.

4. Charon R. Narrative and medicine. N Engl J Med. 2004;350(9):862-4.

5. Schmidt HG, Vermeulen L, van der Molen HT. Longterm effects of problem-based learning: a comparison of competencies acquired by graduates of a problem-based and a conventional medical school. Med Educ. 2006;40(6):562-7.

6. Popper K. A lógica da pesquisa científica. $2^{\text {a }}$ ed. São Paulo: Cultrix; 2013. 454p.

7. Robbs J, Meredith S. The problem-based learning curriculum at Southern Illinois University School of Medicine [Article] 1994. Available from: http://www. suimed.edu/pblc/pblcur.html [link no longer available].

8. Kleinman A. The illness narratives. Suffering, healing \& the human condition. New York: Basic Book; 1988. $284 p$.

9. Frank A. The wounded storyteller. Body, illness and ethics. 2nd ed. Chicago: The University of Chicago Press; 2013. 280p.

10. Hawkins AH. Reconstructing illness. Studies in pathography. Indiana: Perdue University Press; 1999. 289p.

11. Grossman E, Cardoso MHCA. As narrativas em medicina: contribuições à prática clínica e ao ensino médico. Rev bras educ med. 2006;30(1):6-14. 
12. Morris DB. Illness and culture in the postmodern age. Berkeley/Los Angeles/London: The University of California Press; 1998. 360p.

13. Bury M. Illness narratives: fact or fiction? Sociol Health IIIn. 2001;23(3):263-85.

14. Jordens CFC, Little M. In this scenario, I do this, for these reasons: narrative, genre and ethical reasoning in the clinic. Soc Sci Med. 2004;58(9):1635-45.

15. Moretti FA, Oliveira VE, Silva EMK. Acesso a informações de saúde na internet: uma questão de saúde pública? Rev Assoc Med Bras. 2012;58:650-8.

16. Murray E, Burns J, See Tai S, Lai R, Nazareth I. Interactive health communication applications for people with chronic disease. Cochrane Database Syst Rev. 2005;(4):CD004274.

17. Cardoso MHCA. A herança arcaica de um modelo: história, medicina... e a síndrome de Down. [Tese de Doutorado]. Rio de Janeiro: Programa de Pós-Graduação em Saúde da Criança e da Mulher, Instituto Fernandes Figueira, Fundação Oswaldo Cruz; 2000.
18. Hunter KM. Doctor's stories. The narrative structure of medical knowledge. Princeton: University of Princeton Press; 1991. 232p.

19. Donnelly W. The language of medical case histories. Ann Intern Med. 1997;127(11):1045-8.

20. Bakhtin M. Estética da criação verbal. São Paulo: Martins Fontes; 1992. 421p.

\section{Eloisa Grossman}

Instituto Fernandes Figueira. Fundação Oswaldo Cruz. Rio de Janeiro, RJ, Brasil.

Núcleo de Estudos da Saúde do Adolescente. Faculdade de Ciências Médicas. Universidade do Estado do Rio de Janeiro. Rio de Janeiro, Brasil.

\section{Maria Helena C. A. Cardoso}

Grupo de Pesquisa de Genética Médica José Carlos Cabral de Almeida. Instituto Fernandes Figueira. Fundação Oswaldo Cruz. Rio de Janeiro, RJ, Brasil. 